\title{
«No pienses en un oso blanco». Sobre un caso de trastorno de la conducta alimentaria de larga evolución
}

Hoy en día es ampliamente aceptado que la psicoterapia, sola o en combinación con psicofármacos, es el tratamiento de elección en los trastornos del comportamiento alimentario (1) y (2). Aunque la terapia cognitivo-conductual es la más estudiada y la que se propone como de elección (3), (4) y (5), otras modalidades psicoterapéuticas han demostrado su eficacia (6) y (7). Algunos autores hablan de tratamientos secuenciados e integradores (8).

Se presenta el caso de una paciente con diagnóstico de anorexia nerviosa tipo mixto en tratamiento desde hacía 8 años, en la que se aplicó con éxito durante un ingreso una intervención psicoterapéutica en el marco de la Terapia Contextual o Terapia de Aceptación y Compromiso (9), (10) y (11).

La Terapia Contextual o Terapia de Aceptación y Compromiso surge en los años noventa dentro del paradigma conductista radical. Centra la intervención en el contexto verbal que envuelve la conducta, y no en la conducta misma. Parte de las ideas planteadas por Skinner (12) (dentro de la propia corriente conductista), que ya estableció la distinción entre la conducta moldeada por las contingencias y la conducta gobernada por reglas. La intervención no está destinada a la modificación directa de conductas, pensamientos o emociones, sino que está orientada a la modificación del contexto verbal en el cual se dan. De esta forma, la intervención no está destinada a la modificación directa de aquellas conductas, pensamientos o emociones que no pueden modificarse o eliminarse (entre otras cosas porque pueden ser inevitables y aun convenientes en determinadas circunstancias, por lo que hay que aceptarlo). Su objetivo terapéutico consiste en el cambio de la literalidad que el paciente otorga a su conducta verbal, de la explicación que da a su conducta, y la modificación de la valoración y el intento de control del paciente sobre su conducta problema. Las estrategias psicológicas (Hayes, McCurri, Afari y Wilson, 1991) utilizadas a tal efecto consisten particularmente en la intención paradójica y, sobre todo, el uso de metáforas y ejercicios experienciales, así como las pruebas de realidad de lo analizado en terapia (exposición a las contingencias naturales).

\section{Caso:}

Se trata de una paciente de 26 años con diagnóstico de Anorexia Nerviosa subtipo mixto (DSM-IV F50.0) desde los 18 años. La paciente creció en un entorno fami- 
liar caracterizado por el control que sus padres efectuaban con frecuencia sobre su propia conducta. En el colegio fue objeto de burlas por su apariencia física, recordando como significativo el enorme éxito social de su mejor amiga, que destacaba por estar «extremadamente delgada». En el inicio presentaba vómitos ocasionales tras las comidas, hasta llegar a episodios diarios de atracón-vómito y una progresiva restricción alimentaria. El aumento de estos episodios correlacionaba con situaciones vitales ansiógenas (por ejemplo, el día de la boda, los conflictos constantes con su marido, y en general en las relaciones interpersonales), utilizando el atracón como «vía de escape» para los problemas y el control de la ansiedad. El vómito correspondiente cumple la función de evitar el aumento de peso. Previamente se habían puesto en marcha abordajes diversos: tratamiento combinado con psicofármacos (antidepresivos y BDZ a diferentes dosis), psicoterapia de apoyo de orientación dinámica, control periódico del peso, pautas de alimentación por parte del equipo de seguimiento y control del estado nutricional por parte del servicio de endocrinología. Durante un ingreso previo hacía un año en una situación clínica muy similar se llevó a cabo un abordaje psicoterapéutico centrado en analizar los conflictos interpersonales relacionados con las crisis. La recaída se produjo inmediatamente después del alta.

$\mathrm{El}$ ingreso actual se programa con el acuerdo de la paciente por descompensación severa tras un año de abandono del seguimiento ambulatorio a lo que se añade la sensación subjetiva de ineficacia del abordaje psicoterapéutico previo. En el momento en el que se decide el ingreso hospitalario la restricción alimentaria era extrema (con un BMI de 15) y presentaba episodios atracón-vómito cinco veces al día.

Durante la evaluación funcional queda patente que la falta de control sobre la ingesta y los vómitos se relacionan en buena medida con la existencia de pensamientos e imágenes intrusivos relacionados con la comida. La lucha interna por evitar estos pensamientos, las imágenes y la ansiedad perpetuaban la conducta, a pesar de que, lejos de producir alivio, intensificaban más la ansiedad. Esto es lo que Luciano y Hayes denominaron Trastorno de evitación experiencial (Luciano y Hayes, 2001). Según estos autores este trastorno funcional ocurre cuando una persona no está dispuesta a establecer contacto con sus experiencias privadas (estados o sensaciones de su cuerpo, sus pensamientos o recuerdos o sus predisposiciones conductuales) y se comporta deliberadamente para alterar la forma o frecuencia de tales experiencias y las condiciones que las generan. El intento de control mediante la evitación lleva paradójicamente al efecto opuesto: aumenta la intensidad y la frecuencia de esos pensamientos y emociones que trata de evitar.

La hipótesis establecida desde esta perspectiva es que a la paciente le guiaba la regla verbal de evitación (construida culturalmente), según la cual se debe evitar y controlar cualquier evento interno desagradable (ya sean pensamientos, imágenes o emociones). Esta regla verbal, reforzada socialmente (sobre todo en su 
ambiente familiar), lleva a la paciente a afanarse en un intento de control. El propio intento de control (que no se modifica por las consecuencias, al estar guiado por una regla cultural) lleva paradójicamente al efecto opuesto: aumenta la intensidad y la frecuencia de esos pensamientos y emociones que trata de evitar. La terapia de aceptación y compromiso va a la raíz de este problema. El objetivo de esta terapia es cambiar el problema, no la conducta, de modo que puede incluso que la conducta problema no cambie su topografía pero puede, sin embargo, haber cambiado su función, dejando de ser problema. En nuestro caso, la paciente que temía la ansiedad, por ejemplo, no tiene por qué no seguir teniendo ansiedad (en aquellos casos en que sea inevitable o apropiada), pero lo decisivo es que no la teme. Al no temerla no la tiene como problema.

Tomando como punto de partida esta hipótesis se planificó la intervención utilizando herramientas de la Terapia de Aceptación y Compromiso. A diferencia de otras estrategias en el marco de la terapia cognitivo-conductual, el objetivo no fue cambiar o extinguir la conducta (ganas de atracón, pensamientos e imágenes mentales de comida, y la ansiedad), sino producir cambios en el problema (rígidos intentos de control). Se plantearon las siguientes metas terapéuticas (13):

1.-Establecer un estado de desesperanza creadora, frustrando las pretensiones de la paciente de evitar los pensamientos y la ansiedad.

2.-Señalar el control como parte del problema y proponer ejercicios experienciales.

3.-Diferenciar entre la persona y la conducta.

4.-Abandonar la lucha contra las emociones y pensamientos, lo que supone aceptarlos.

5.-Establecer un compromiso de actuar en la dirección de sus valores personales, sin que la evitación de experiencias trastorne su camino en la vida.

Los cambios se objetivaron ya a lo largo del ingreso. La paciente comenzó a tolerar la presencia de los pensamientos e imágenes relacionados con la comida y la ansiedad en determinados momentos del día. Posteriormente consiguió abandonar la lucha contra ellos hasta que desaparecieron. En los seguimientos que se realizaron tras el alta se mantenía la mejoría en este sentido. La frecuencia y magnitud de los atracones se había reducido a tres a la semana, que se reflejó en un aumento mantenido del peso en un rango más saludable $(\mathrm{BMI}=17)$.

\section{Discusión:}

La terapia contextual o terapia de aceptación y compromiso no se ha practicado tradicionalmente en casos de trastornos de la conducta alimentaria. Consideramos 
que puede ser útil la aplicación de determinadas estrategias procedentes de esta modalidad terapéutica en el marco de un programa de tratamiento global diseñado a partir de una formulación del caso desde una perspectiva integradora.

En este caso el abordaje de las conductas restrictivas y de atracón-vómito con esta herramienta terapéutica se ha mostrado eficaz para lograr los objetivos propuestos para el alta y para la prevención de recaídas a medio plazo. Sin embargo, existen otros aspectos en las áreas de las relaciones interpersonales y de la identidad que necesitarán un abordaje posterior.

El éxito de la intevención en esta paciente puede ser explicado en base a varios factores que pueden ser tenidos en cuenta para otros posibles casos:

1.-La fase del proceso de cambio en el que se encuentra la paciente en el momento del ingreso. Según el modelo de Prochaska y DiClemente, nos encontramos a la paciente en un estadio de acción, donde las intervenciones de orientación conductual se proponen como las más eficaces.

2.-El análisis funcional guía los objetivos y estrategias terapéuticas a utilizar en cada caso. La aplicación manualizada de estrategias (por ejemplo cognitivoconductuales) en función de una etiqueta diagnóstica (un trastorno de alimentación) está destinada al fracaso.

\section{BIBLIOGRAFÍA}

(1) Gore, S. A.; VAnder, J.; Thelen, M. H., «Treatment of Eating Disorders in Children and Adolescents», Body Image, Eating Disorders and Obesity in Youth, 2001, A.P.A., Washington D.C.

(2) Robin, A.; Gilroy, M.; BaKer, D., «Treatment of Eating Disorders in Children and Adolescents», Clinical Psychological Review, 1998, 18, pp. 421-446.

(3) Calvo, R., Anorexia y Bulimia: Guía para padres, educadores y terapeutas, Planeta Prácticos, 2002.

(4) Cumming, M., y otros, «Developing and Implementing a Comprehensive Program for Children and Adolescent with Eating Disorders», Adolescent Psychiatric Nursing, 2001, 14, 3, pp. 167-178.

(5) Steiner, H., «Anorexia Nervosa and Bulimia Nervosa in Children and Adolescents: a Review of the Past 10 Years», J.A.A., Child and Adolescent Psychiatric, 1998.

(6) FAIRBURN, Ch., «Interpersonal Psychotherapy for Bulimia Nervosa», en GARnER, D. M.; Garfinkel, P. E., Handbook of Treatment for Eating Disorders, NuevaYork, the Gilford Press, 1997.

(7) Dare, C.; EIsler, I., «Family Therapy for Anorexia Nervosa», en Garner, D. M.; Garfinkel, P. E., Handbook of Treatment for Eating Disorders, Nueva York, the Gilford Press, 1997.

(8) Garner, D. D.; Needleman, L. D., Sequencing and Integration of Treatments, en Garner, D. M.; Garfinkel, P. E., Handbook of Treatment for Eating Disorders, NuevaYork, the Gilford Press, 1997.

(9) HaYes, S. C., y otros, Acceptance and Commitment Therapy. A Therapy Manual for the Treatment of Emotional Avoidance, Reno, Context Press, 1991. 
(10) HAYEs, S. C.; WiLson, K., «Some Applied Implication of a Contemporary BehaviorAnalytic Account of Verbal Events», The Behavior Analyst, 1993, 16, pp. 283-301.

(11) LuCIANo, C.; HaYes, S. C., «Trastorno de evitación experiencial», Revista Internacional de Psicología Clínica y de la Salud, 2001, 1, pp. 109-157.

(12) SkInNeR, B. F., Verbal Behavior, Nueva York, Appleton-Century-Crofts, 1957.

(13) HAYES, S. C., «A Contextual Approach to Therapeutic Change», en JACOBSON, N. (ed.), Psychoterapist in Clinical Practice Cognitive and Behavioral Perspective, 1984, Nueva York, Guilford Press.

* Marcos López Hernández-Ardieta, P.I.R.; María Diéguez Porres, psiquiatra. Hospital Príncipe de Asturias de Alcalá de Henares. Correspondencia: mlopez.ha@gmail.com ** Fecha de recepción: 12-XII-06. 